\title{
Manipulation of plant odour preference by learning in the aphid parasitoid Aphelinus abdominalis (Hymenoptera: Aphelinidae)
}

\author{
GunNar MÖLCK, Helga PINN and URs WYSS* \\ Institute of Phytopathology, University of Kiel, Hermann-Rodewald-Str. 9, D-24118 Kiel, Germany
}

Key words. Aphelinus abdominalis, aphid parasitoid, wind tunnel, Macrosiphum euphorbiae, Capsicum annuum, Solanum melongena, host location, plant-host complex, learning, synomones

\begin{abstract}
Aphelinus abdominalis Dalman (Hymenoptera: Aphelinidae), a solitary endoparasitoid of cereal aphids [e.g. Sitobion avenae (F.)] and aphids in greenhouses [e.g. Myzus persicae (Sulzer) and Macrosiphum euphorbiae (Thomas)] is available as biological control agent against aphid pests in greenhouses. As little is yet known about its long-range host location after release, the inflight orientation of female $A$. abdominalis was investigated with regard to the effects of post-emergence experience, using a wind tunnel bioassay. In no-choice tests experienced females responded to the odour of $M$. euphorbiae-infested sweet pepper and aubergine plants while naive females exhibited mostly random flights. In a choice test, offering infested and uninfested plants of the same species, experienced wasps were able to recognize the plant-host complex (PHC) and selected it as landing site. In contrast to uninfested plants, host-damaged plants (infested plants with aphids removed) attracted experienced females just as well as infested plants. When the responses of groups of parasitoids with experience on two different plant-host complexes were studied, specifically trained wasps were observed to orientate significantly better towards the infested target plant than wasps with previous experience on the non-target plant. A final choice test, with an infested pepper and an infested aubergine plant as odour sources, showed that females trained on one of the offered plant-host combinations significantly preferred the odour of the learnt PHC to that of the different PHC. The results suggest that $A$. abdominalis females employ specific volatile signals emitted by host-infested plants (synomones) during long-range host location. These odours must be learnt, e.g. in association with a successful oviposition.
\end{abstract}

\section{INTRODUCTION}

Since the discovery that herbivore-infested plants emit specific volatile semiochemicals (synomones; Nordlund, 1981) that are used as cues by predators and parasitoids to locate their prey or host (Dicke \& Sabelis, 1988; Turlings et al., 1990), considerable attention has been paid to this aspect of induced indirect defence of plants towards herbivore attack. It is therefore not surprising that this has been documented in an increasing number of tritrophic systems within the past ten years (most recently reviewed by Dicke (1999a), Dicke \& Vet (1999), Paré \& Tumlinson (1999) and Vet (1999)). The release of synomones is triggered by the interaction of elicitors in the oral secretions of the herbivores with damaged plant tissue (reviewed in Tumlinson et al., 1999) and in most cases is also systemically expressed (Dicke, 1999b). Most known examples of induced indirect plant defence deal with the interaction between caterpillars and their parasitic wasps (reviewed in Turlings et al., 1995; Turlings \& Fritzsche, 1999) and spider mites and predatory mites (reviewed in Takabayashi \& Dicke, 1996). Although aphids inflict only minor mechanical damage on the plant tissue, a number of recent studies have clearly demonstrated that they also induce the emission of plant volatiles that attract aphidiine wasps (Guerrieri et al., 1993, 1999; Micha \& Wyss, 1995; Du et al., 1996, 1998; Powell et al., 1998).
The use of chemical cues for olfactory orientation of parasitoids can be genetically fixed but numerous studies showed that learning of profitable cues may often be of equal importance to enable the foraging female to adapt quickly to changes in environmental conditions. Associative learning is commonly described as a temporary behavioural modification, mostly connected to a rewarding stimulus (Godfray, 1994) and has been documented for various parasitoid species (e.g. Vinson et al., 1977; Vet \& Groenewold, 1990; Monge \& Cortesero, 1996; Du et al., 1997; Grasswitz, 1998; Couty et al., 1999). However, sometimes the effects of associative learning and sensitization, an increased response to an innately recognized stimulus (also termed priming, s. Turlings et al., 1993), can be only poorly distinguished by behavioural experiments. Among the criteria recommended by Papaj \& Prokopy (1989) in order to specify learning, it was suggested that the behavioural change may be gradually reinforced with continued experience but may wane in the absence of such experience.

In an earlier study, employing a Y-tube olfactometer, we have shown that females of the aphelinid wasp Aphelinus abdominalis respond to the odour of sweet pepper plants infested by the aphid host $M$. euphorbiae, preferring it to the odour of uninfested plants (Mölck et al., 1999), probably due to the emission of synomones. As only females with oviposition experience on the plant-

\footnotetext{
* Correspondence: Professor Dr. U. Wyss, Institut für Phytopathologie, Universität Kiel, Hermann-Rodewald-Str. 9, D-24118 Kiel, Germany; e-mail: uwyss@phytomed.uni-kiel.de
} 
host complex, but not those with oviposition experience in a plant-odour free environment orientated towards the odour blend of infested plants, it was suggested that associative learning might be involved, though priming could not be excluded entirely.

In this study we examined the in-flight orientation of $A$. abdominalis females in a series of wind tunnel experiments. Our goal was to find out how the response of the parasitoids to the odour of infested plants was affected by post-emergence experience with two different plant-host combinations.

\section{MATERIALS AND METHODS}

\section{Rearing}

Sweet pepper (Capsicum annuum, cv. 'Pusztagold') and aubergine plants (Solanum melongena, cv. 'Lange Violette') were grown in gauze cages at a $16 \mathrm{~L}: 8 \mathrm{D}$ photoperiod, $20^{\circ} \mathrm{C}$ $\left( \pm 1^{\circ} \mathrm{C}\right)$ and at $60-70 \%$ r.h. in climatic chambers. Aphid cultures of $M$. euphorbiae on sweet pepper and aubergine plants were kept at $16 \mathrm{~L}: 8 \mathrm{D}$ light regime, $20^{\circ} \mathrm{C}\left( \pm 1^{\circ} \mathrm{C}\right)$ and $50-60 \%$ r.h. A. abdominalis was reared on grain aphids (Sitobion avenae) feeding on wheat plants (Triticum aestivum, cv. Troll) under the same environmental conditions. The different host system for the parasitoid cultures was chosen to prevent any interference of pre-adult or emergence-related experience with the oviposition experience treatments.

After pupation, mummies were removed from the leaves and transferred into gauze-covered acrylic cylinders that were placed on plastered pots. Emerged wasps were kept in these tubes with a supply of $15 \%$ sucrose solution at $16 \mathrm{~L}: 8 \mathrm{D}$ photoperiod, $20^{\circ} \mathrm{C}\left( \pm 1^{\circ} \mathrm{C}\right)$ and at $50-60 \%$ r.h. until being used in the experiments.

\section{Experimental plants}

4-5 week old sweet pepper and aubergine plants were inoculated with aphids to prepare them for later use in the experiments or the experience treatments. After three days, when the experiments were performed, the aphid infestation level was adjusted to 150-200 aphids of all instars.

\section{Parasitoid experience}

Mated, 3-7 day old female parasitoids taken from the emergence tubes were allowed to forage for two hours on aphidinfested plants (sweet pepper or aubergine, according to the experimental treatment) placed under an acrylic cylinder. During this period they had the opportunity to oviposit and to perform host-feeding as well. Thereafter, the parasitoid females were removed from the plants and put into small acrylic tubes closed with moist cotton pads and kept there in groups of 10 for a resting period of four hours. As demonstrated by preliminary trials, this resting period clearly increased the responsiveness of the females in the wind tunnel. Naive females were kept without any contact with aphids or plants and prior to the experiments they were stored under the same conditions as the experienced animals.

\section{Wind tunnel}

The flight behaviour of $A$. abdominalis females was studied in a wind tunnel similar to the one described by Miller \& Roelofs (1978). The flight chamber consisted of an acrylic box, $100 \mathrm{~cm}$ in length and $40 \mathrm{~cm}$ in width and height. The circulating air flow, generated by an electrically operating fan, was passed through a mechanical dust filter and a filter of activated charcoal to cleanse the air. A porous metal plate and two sheets of finely meshed gauze at each end of the flight chamber ensured the laminarity of the air flow. Parasitoids were released on a small glass platform $(15 \times 20 \mathrm{~cm})$ resting on an acrylic cylinder $15 \mathrm{~cm}$ above the ground of the chamber. Wind speed was adjusted to $25 \mathrm{~cm} / \mathrm{s} \pm 2 \mathrm{~cm}$ at the releasing site. The wind tunnel was kept in a climatic chamber under constant environmental conditions $\left(22 \pm 1^{\circ} \mathrm{C}, 65 \pm 5 \%\right.$ r.h., 1,900 lux). The plants used as odour sources were positioned $20 \mathrm{~cm}$ upwind of the brim of the release platform. The flight chamber was accessible through two small flaps in the sides of the acrylic box.

\section{Experimental procedure}

In all experiments the parasitoid females were transferred into small gelatine capsules $\left(0.95 \mathrm{~cm}^{3}\right)$ in order to introduce them singly into the wind tunnel. After release at the center of the platform the behaviour of the wasp was observed for a maximum time of $10 \mathrm{~min}$. The observation was cancelled if the wasp left the platform by walking or leaping. If flying occurred, then only the first flight was recorded with respect to orientation and landing site. Flights directed towards the odour source were defined as oriented flights. Landings were scored if the wasps landed on the plant, including the pot. When observing the response of differently treated parasitoids, females of either treatment group were always tested alternately. Target plants were exchanged after each block of 5-6 parasitoids observed. All experiments were conducted on several consecutive days and the wind tunnel was thoroughly cleaned with detergent and alcohol prior to the introduction of any new odour source.

In the first experiment the flight behaviour of experienced and naive females was compared, offering a single aphid-infested plant as odour source, either sweet pepper or aubergine.

The second experiment was designed to offer the females the choice between an infested and an uninfested plant that were placed next to each other in the wind tunnel. Again, the responses and landing decisions of naive and experienced females were tested, using sweet pepper or aubergine plants in separate trials.

In the third experiment the attractiveness of three differently treated sweet pepper plants for experienced females was tested in a no-choice experiment. Uninfested plants, infested plants and host-damaged plants served as odour sources. Hostdamaged plants were prepared by removing all aphids and exuviae carefully from the leaves of an infested plant with a brush immediately before the experiment was started. However, honeydew was not washed off in order to avoid any mechanical damage to the leaves.

In the fourth experiment the flight response of females experienced with $M$. euphorbiae on either sweet pepper or aubergine was studied, offering one of the plant-host complexes in separate experimental blocks in a no-choice setup (Table 1).

TABLE 1. Design of experiment 4 (no-choice), experience on different host plant species.

\begin{tabular}{ccc}
\hline Series & Experience treatment & Odour source \\
\hline a & sweet pepper + M.euphorbiae & sweet pepper + M. euphorbiae \\
& aubergine + M.euphorbiae & \\
b & sweet pepper + M.euphorbiae & aubergine + M. euphorbiae \\
& aubergine + M.euphorbiae & \\
\hline
\end{tabular}

The fifth experiment was conducted as choice test between a sweet pepper and an aubergine plant, both infested with $M$. euphorbiae. Again, two groups of female wasps, each experienced with one of the two plant-host complexes, were observed. The choice of all females landing on one of the odour sources was recorded. 

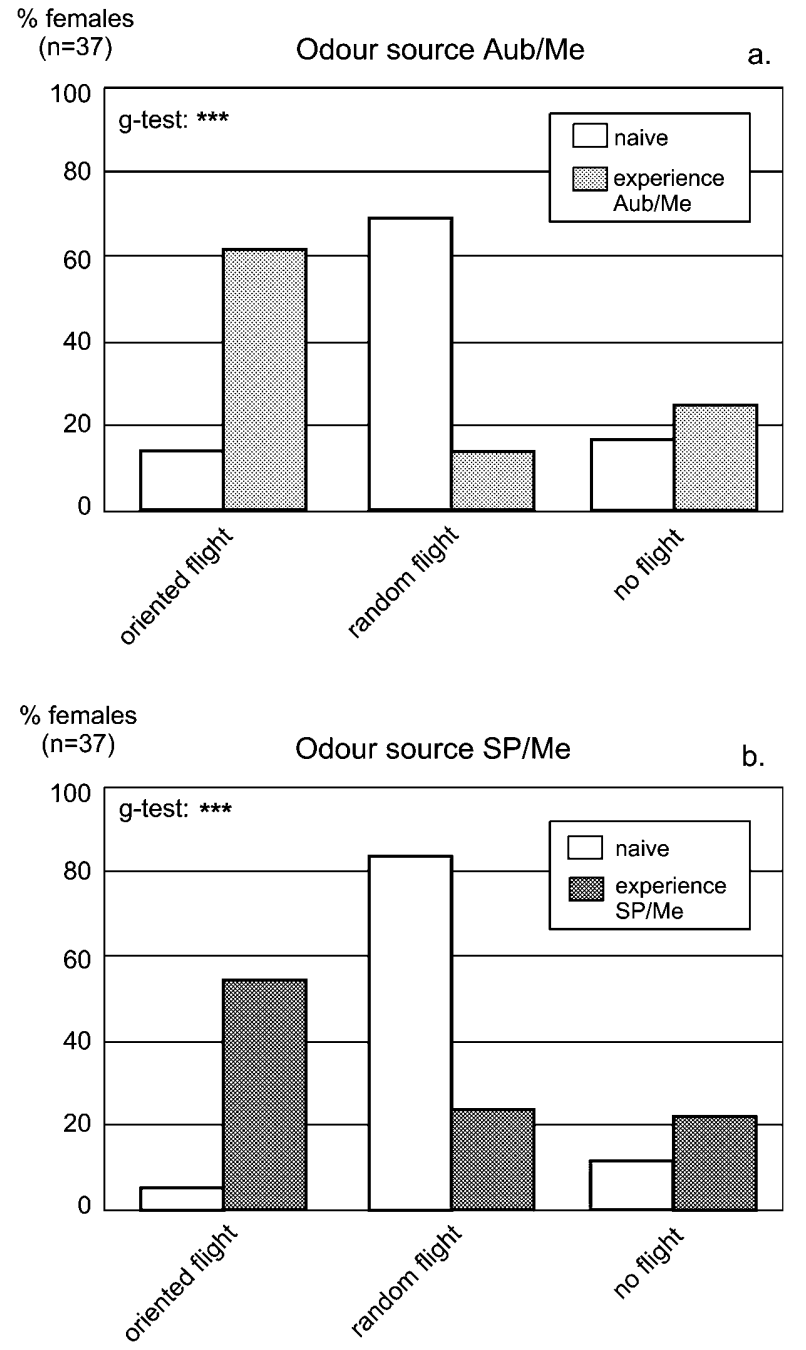

Fig. 1a-b: a - Response of naive and experienced $A$. abdominalis females in the wind tunnel with an aubergine plant (Aub) infested with $M$. euphorbiae (Me) as odour source. Distribution of flight responses is significantly different between naive and plant-host experienced females (G-test; $\mathrm{p}<0.001) . \mathrm{b}-$ Response of naive and experienced $A$. abdominalis females in the wind tunnel with a sweet pepper plant (SP) infested with $M$. euphorbiae (Me) as odour source. Distribution of flight responses is significantly different between naive and plant-host experienced females (G-test; $\mathrm{p}<0.001)$.

Statistical analysis of the choice tests (choice of landing site) was carried out with a Chi-Square Goodness-of-Fit test $(\alpha=0.05$ ). The general flight responses of different treatments were compared using contingency tables (G-test).

\section{RESULTS}

In the first experiment, experienced females showed a fairly high proportion of oriented flights, followed by landings on the plant. In contrast, random flights were recorded for most of the naive females that took off from the release platform. The behavioural differences of the two groups of tested females were highly significant
( $\mathrm{p}<0.001)$ for both odour sources offered (infested aubergine, infested sweet pepper, Fig. 1a and b).

In the second experiment (Fig. 2), naive and experienced parasitoids were offered two plants - one infested, one uninfested - as odour sources. As in the first experiment, naive females exhibited many random flights and few oriented flights towards the target plants. A major proportion of the experienced females landed on one of the plants, fewer wasps flew randomly downwind. As the distribution of flight responses was very similar to the results of the previous no-choice experiment, only the results of the choice of the landing females between the two plants are shown in Fig. 2.

The attractiveness of infested, host-damaged and uninfested sweet pepper plants was examined in experiment 3 in a no-choice setup. The results (Fig. 3) document an equally high level of orientation of the experienced females towards the infested plant as well as towards the host-damaged plant. However, significantly fewer landings were recorded for uninfested plants $(p<0.001)$ while a large number of females did not even leave the release platform.

In the fourth experiment, two groups of wasps, experienced on either sweet pepper or aubergine, were tested with regard to their orientation towards one specific plant-host complex (Table 1). The results (Fig. 4a and b) show that the responsiveness of the specifically experienced females shifted depending on the tested odour source. When using an infested aubergine plant as odour source (Fig. 4a), the majority of the aubergineexperienced females flew off the platform towards the plant while more than half of the sweet pepperexperienced wasps refused to take off during observation. Exchanging the odour source for an infested sweet pepper plant (Fig. 4b), the results were reversed. A significantly higher proportion of sweet pepper-experienced females responded by exhibiting oriented flights towards the plant

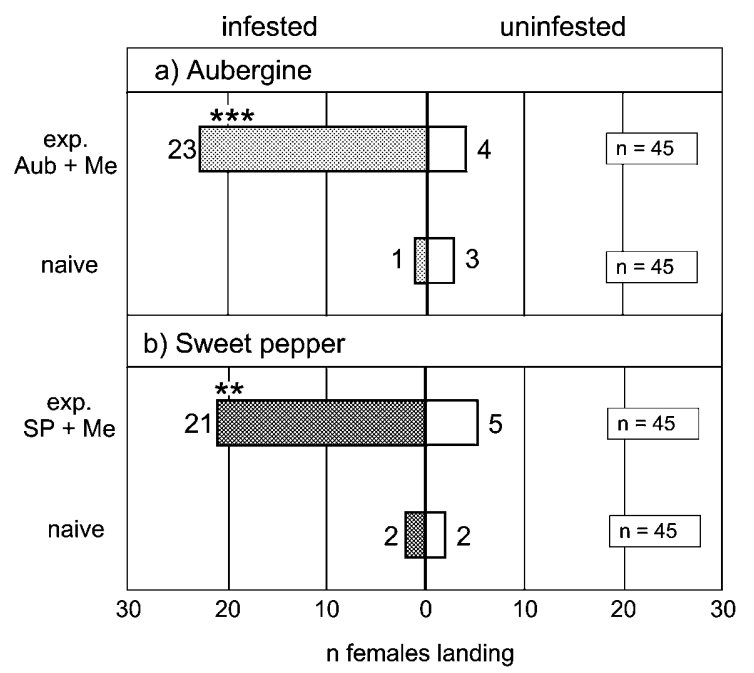

Fig. 2. Landing choice of naive and experienced $A$. abdominalis females between an infested $(\mathrm{Me}=M$. euphorbiae) and an uninfested plant of (a) aubergine (Aub) and (b) sweet pepper (SP) in the wind tunnel. Stars indicate level of significance $\left({ }^{* *}: \mathrm{p}<0.01,{ }^{* * *}: \mathrm{p}<0.001\right.$, goodness-of-fit). 


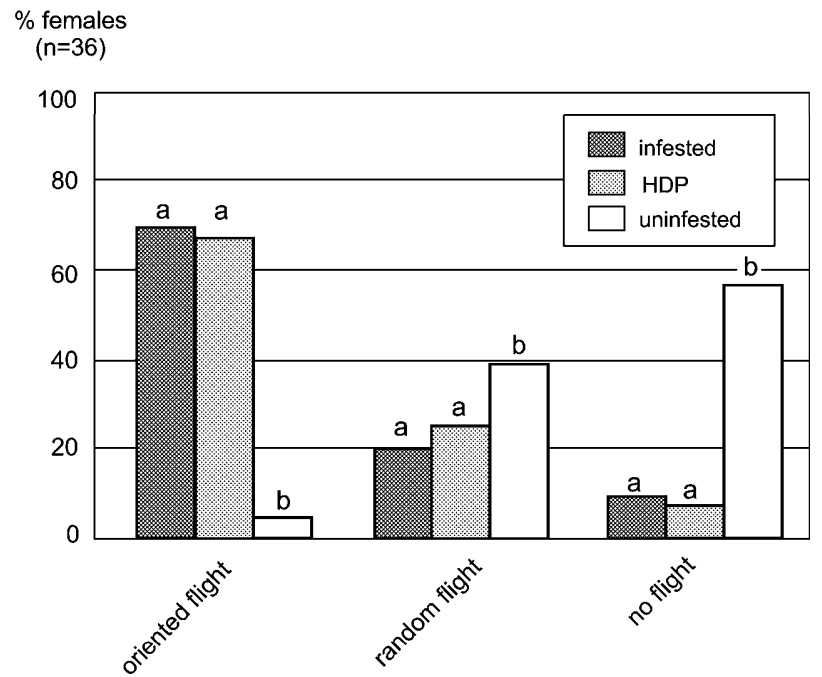

Fig. 3. Attraction of sweet pepper-experienced A. abdominalis females to different odour sources. The three sweet pepper plant treatments compared were: Infested plants, host-damaged plants (HDP) and uninfested plants. Distributions represented by bars with same letters are not significantly different (G-test).

and most of the aubergine-experienced wasps completely failed to respond.

These results of experiment 4 were confirmed by the choice test in the fifth experiment (Fig. 5). Females of both groups responded significantly only to the odour of the plant-host complex (PHC) they encountered during their previous experience treatment.

\section{DISCUSSION}

In a previous study, using a $\mathrm{Y}$-olfactometer, responses of $A$. abdominalis females to the odour of infested plants were highly dependent on an earlier oviposition experience (Mölck et al., 1999). These results are confirmed in the present study, using a wind tunnel bioassay. For both combinations of plant and host aphid (sweet pepper/M. euphorbiae; aubergine/M. euphorbiae) it became evident that experienced females use the odour emanating from the plant-host complex for the location of the infested plant while flying. In contrast, naive females failed to respond to the offered chemical cues (experiment 1). After an oviposition experience with the appropriate plant-host complex, females were able to distinguish between infested and uninfested plants in a choice situation (experiment 2), indicating that infested plants emit volatiles not present in the blend of uninfested plants. This experiment demonstrates that olfactory cues are obviously more important in host habitat location from a distance than visual cues which otherwise may also contribute to the in-flight orientation of parasitoids (Guerrieri, 1997; Wäckers \& Lewis, 1994). The results of experiment 3 complement those of previous olfactometer studies by Mölck et al. (1999), who found no attraction of female $A$. abdominalis to host aphids alone and also no attraction to the plant-host complex if the oviposition experience was not given on a plant. Altogether, these data provide sufficient evidence that it is not the aphids but the plant volatiles induced by their feeding activities that are the attractive cues for searching aphid parasitoids (see also review by Wadhams et al., 1999).

Experiment 4 demonstrates that the orientation of the females to a plant-host complex is only enhanced after they have gained a specific experience with the same plant-aphid combination. Therefore, the oviposition experience did not just increase the general responsiveness of the wasps to innately recognized cues (priming, Turlings et al., 1993) but obviously triggered associative learning of at least part of the odour blend present during host encounter. The plant-species specificity of the signals learnt during oviposition experience most likely excludes

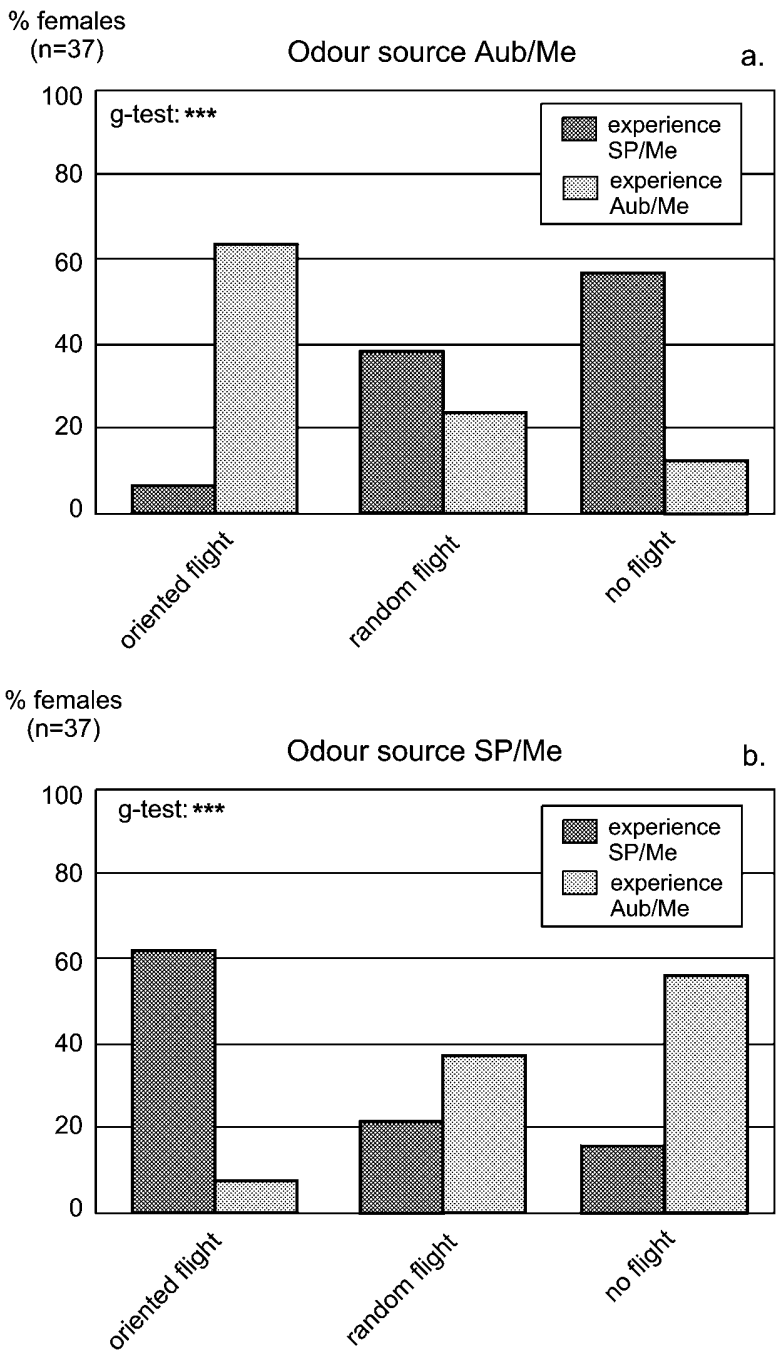

Fig. 4a-b: a - Response of sweet pepper-experienced and aubergine-experienced $A$. abdominalis females in the wind tunnel with an aubergine plant (Aub) infested with $M$. euphorbiae (Me) as odour source. Distribution of flight responses is significantly different between both groups of specifically experienced females (G-test; $p<0.001$ ). $\mathrm{b}$ - Response of sweet pepper-experienced and aubergine-experienced $A$. abdominalis females in the wind tunnel with a sweet pepper plant (SP) infested with $M$. euphorbiae (Me) as odour source. Distribution of flight responses is significantly different between both groups of specifically experienced females (G-test; $\mathrm{p}<0.001)$. 


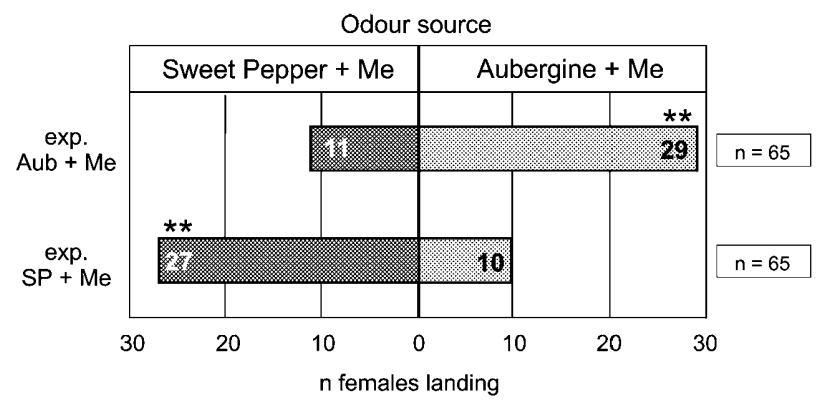

Fig. 5. Landing choice of aubergine-experienced and sweet pepper-experienced $A$. abdominalis females between an infested $(\mathrm{Me}=M$. euphorbiae $)$ aubergine and an infested sweet pepper plant in the wind tunnel. Stars indicate level of significance (**: $\mathrm{p}<0.01$, goodness-of-fit).

the possibility that honeydew may be an additional important source of attractants used by the parasitoids in longrange orientation.

The results of the choice test between both tested planthost combinations (experiment 5) document that the odour preference of $A$. abdominalis can be manipulated in favour of a specific plant species. Similar results have recently been reported by Geervliet et al. (1998) who studied the responses of the braconid Cotesia glomerata towards different varieties of cabbage infested with Pieris brassicae-larvae. The chemical analysis of the odour blends of the infested plants will finally answer the question which volatile compounds are actually learnt in this process. According to Geervliet et al. (1997) the volatile blend is more affected by the food plant species than by the herbivore species. Caterpillar infestation induced the emission of higher amounts of plant volatiles and in some cases also a larger number of components. Du et al. (1998) identified some semiochemicals released by aphidattacked bean plants shown to be attractive to the aphid parasitoid Aphidius ervi. A more detailed knowlegde of the chemical compounds involved in the learning process of $A$. abdominalis would greatly improve our understanding of the mechanisms that determine the hostlocation efficiency of this parasitoid.

A. abdominalis attacks a wide range of host aphid species feeding on many distinct plants. In a natural environment the availability and abundance of suitable aphid host colonies may change rapidly in time. As hypothesized by some authors (e.g. Geervliet et al.,1998), a generalist parasitoid may benefit greatly from its behavioural plasticity to change its host-searching strategy according to environmental conditions. Consequently, associative learning would be of considerable adaptive value for A. abdominalis. After emergence, parasitoid females need instant and reliable information about current environmental conditions which may help them to carefully assign their resources (energy, egg load etc.) in order to produce a maximum number of viable progeny. The first host encounters may provide such crucial information for the female and a successful oviposition is often assumed to be the necessary reinforcing stimulus for learning (Geervliet et al., 1994). In the present study we focussed only on the effects of oviposition experience, although it is known from other studies that parasitoids may employ other host-derived cues as reinforcing stimuli to induce learning. Host faeces - e.g. honeydew - is generally considered to contain chemical signals that influence the short-range searching behaviour of parasitoids, thus acting as contact kairomones (e.g. Ayal, 1987; Budenberg, 1990; Romeis \& Zebitz, 1997). If contact with aphid honeydew can stimulate associative learning in $A$. abdominalis remains to be examined. Future investigations should also focus on the question of how an unrewarding experience, e.g. probing of already parasitized hosts, may affect the females' motivation to learn (Papaj et al., 1994). The final goal will be to develop strategies of how the efficiency of aphid parasitoids obtained from a typical mass-rearing environment can be optimized for the biological control of aphids in greenhouses.

ACKNOWLEDGEMENTS. We thank M. Hommes, Biologische Bundesanstalt, D-Braunschweig and Öre-Bioprotect, D-Raisdorf for providing $M$. euphorbiae and A. abdominalis, respectively. G.M. was supported by the Deutsche Forschungsgemeinschaft (DFG, Wy 9/18-1).

\section{REFERENCES}

AYaL Y. 1987: The foraging strategy of Diaeretiella rapae. I. The concept of the elementary unit of foraging. J. Anim. Ecol. 56: $1057-1068$

Budenberg W.J. 1990: Honeydew as a contact kairomone for aphid parasitoids. Entomol. Exp. Appl. 55: 139-147.

Couty A., Kaiser L., Huet D. \& Pham-Delegue M.H. 1999: The attractiveness of different odour sources from the fruit-host complex on Leptopilina boulardi, a larval parasitoid of frugivorous Drosophila spp. Physiol. Entomol. 24: 76-82.

Dicke M. \& SABELIS M.W. 1988: How plants obtain predatory mites as bodyguards. Neth. J. Zool. 38: 148-165.

Dicke M. 1999a: Evolution of induced indirect defense of plants. In Tollrian R. \& Harvell C.D. (eds): The Ecology and Evolution of Inducible Defenses. Princeton University Press, Princeton, NJ, pp. 62-88.

Dicke M. 1999b: Specificity of herbivore-induced plant defences. In Chadwick D.J. \& Goode J.A. (eds): Insect-Plant Interactions and Induced Plant Defence, (Novartis Foundation Symposium 223). Wiley, Chichester, pp. 43-59.

Dicke M. \& Vet L.E.M. 1999: Plant-carnivore interactions: evolutionary and ecological consequences for plant, herbivore and carnivore. In Olff H., Brown V.K. \& Drent R.H. (eds): Herbivores: Between Plants and Predators. Blackwell Science, Oxford, pp. 483-520.

Du Y.-J., Poppy G.M. \& Powell W. 1996: Relative importance of semiochemicals from first and second trophic levels in host foraging behavior of Aphidius ervi. J. Chem. Ecol. 22: 1591-1605.

Du Y., Poppy G.M., Powell W. \& Wadhams L.J. 1997: Chemically mediated associative learning in the host foraging behavior of the aphid parasitoid Aphidius ervi (Hymenoptera: Braconidae). J. Insect Behav. 10: 509-522.

Du Y., Poppy G.M., Powell W., Pickett J.A., Wadhams L.J. \& WoodCock C.M. 1998: Identification of semiochemicals released during aphid feeding that attract parasitoid Aphidius ervi. J. Chem. Ecol. 24: 1355-1368.

Geervliet J.B.F., AriËns S.J.A., Vet L.E.M. \& Dicke M. 1994: Learned odour preferences in the parasitoid Cotesia glomerata. Norw. J. Agric. Sci. 16: 261-267. 
Geervliet J.B.F., Posthumus M.A., Vet L.E.M. \& Dicke M 1997: Comparative analysis of headspace volatiles from different caterpillar-infested or uninfested food plants of Pieris species. J. Chem. Ecol. 23: 2935-2954.

Geervilet J.B.F., Vreugdenhil A.I., Dicke M. \& Vet L.E.M. 1998: Learning to discriminate between infochemicals from different plant-host complexes by the parasitoids Cotesia glomerata and C. rubecula. Entomol. Exp. Appl. 86: 241-252.

Godfray H.C.J. 1994: Parasitoids: Behavioral and Evolutionary Ecology. Princeton University Press, New Jersey, 473 pp.

Grasswitz T.R. 1998: Effect of adult experience on the hostlocation behavior of the aphid parasitoid Aphidius colemani Viereck (Hymenoptera: Aphidiidae). Biol. Control 12 177-181.

Guerrieri E., Pennacchio F. \& Tremblay E. 1993: Flight behaviour of the aphid parasitoid Aphidius ervi (Hymenoptera: Braconidae) in response to plant and host volatiles. Eur. J. Entomol. 90: 415-421

GUERRIERI E. 1997: Flight behaviour of Encarsia formosa in response to plant and host stimuli. Entomol. Exp. Appl. 82: $129-133$

Guerrieri E., Poppy G.M., Powell W., Tremblay E. \& PennacCHIO F. 1999: Induction and systemic release of herbivoreinduced plant volatiles mediating in-flight orientation of Aphidius ervi. J. Chem. Ecol. 25: 1247-1261.

MicHA S.G. \& WYss U. 1995: Bedeutung von Pflanzenduftstoffen bei der Wirtssuche von Aphidius uzbekistanicus (Hymenoptera, Aphidiidae), eines Parasitoiden der Großen Getreideblattlaus (Sitobion avenae). Gesunde Pflanzen 47: 300-307.

Miller J.R. \& Roelofs W.L. 1978: Sustained-flight tunnel for measuring insect responses to wind-borne sex pheromones. $J$. Chem. Ecol. 4: 187-198.

Mölck G., Micha S.G. \& WYss U. 1999: Attraction to odour of infested plants and learning behaviour in the aphid parasitoid Aphelinus abdominalis. J. Pl. Diseases Prot. 106: 557-567.

Monge J.P. \& CORTESERo A.M. 1996: Tritrophic interactions among larval parasitoids, bruchids and Leguminosae seeds; influence of pre- and post-emergence learning on parasitoids' response to host and host-plant cues. Entomol. Exp. Appl. 80: 293-296.

NoRDLUND D.A. 1981: Semiochemicals: A review of the terminology. In Nordlund D.A., Jones R.L. \& Lewis W.J. (eds): Semiochemicals, Their Role in Pest Control. Wiley \& Sons, New York, pp. 13-28.

PAPAJ D.R. \& Prokopy R.J. 1989: Ecological and evolutionary aspects of learning in phytophagous insects. Annu. Rev. Entomol. 34: 315-350.

Papaj D.R., Snellen H., Swaans K. \& Vet L.E.M. 1994: Unrewarding experiences and their effect on foraging in the parasitic wasp Leptopilina heterotoma (Hymenoptera: Eucoilidae). J. Insect Behav. 7: 465-481.

Paré P.W. \& Túmlinson J.H. 1999: Plant volatiles as a defense against insect herbivores. Pl. Physiol. 121: $325-331$.

Powell W., Pennacchio F., Poppy G.M. \& Tremblay E. 1998: Strategies involved in the location of hosts by the parasitoid
Aphidius ervi Haliday (Hymenoptera: Braconidae: Aphidiinae). Biol. Control 11: 104-112.

RomeIs J. \& ZeBrtz C.P.W. 1997: Searching behaviour of Encarsia formosa as mediated by colour and honeydew. Entomol. Exp. Appl. 82: 299-309.

TAKABAYASHI J. \& DiCKe M. 1996: Plant-carnivore mutualism through herbivore-induced carnivore attractants. Trends $P l$. Sci. 1: 109-113.

Tumlinson J.H., Paré P.W. \& Lewis W.J. 1999: Plant production of volatile semiochemicals in response to insect-derived elicitors. In Chadwick D.J. \& Goode J.A. (eds): Insect-Plant Interactions and Induced Plant Defence, (Novartis Foundation Symposium 223). Wiley, Chichester, pp. 95-109.

TurLings T.C.J., Tumlinson J.H. \& LewIS W.J. 1990: Exploitation of herbivore-induced plant odors by host-seeking parasitic wasps. Science 250: 1251-1253.

Turdings T.C.J., WÄcKers F.L., Vet L.E.M., Lewis W.J. \& TumLINSON J.H. 1993: Learning of host-finding cues by hymenopterous parasitoids. In Papaj D.R. \& Lewis A.C. (eds): Insect Learning: Ecological and Evolutionary Perspectives. Chapman \& Hall, New York, pp. 51-78.

Turlings T.C.J., Loughrin J.H., McCall P.J., Röse U.S.R., LEWIS W.J. \& TumLinson J.H. 1995: How caterpillar-damaged plants protect themselves by attracting parasitic wasps. Proc. Nat. Acad. Sci. USA 92: 4169-4174.

TurLings T.C.J. \& Fritzsche M.E. 1999: Attraction of parasitic wasps by caterillar-damaged plants. In Chadwick D.J. \& Goode J.A. (eds): Insect-Plant Interactions and Induced Plant Defence, (Novartis Foundation Symposium 223). Wiley, Chichester, pp. 21-38.

Vet L.E.M. \& Groenewold A.W. 1990: Semiochemicals and learning in parasitoids. J. Chem. Ecol. 16: 3119-3135.

VET L.E.M. 1999: Evolutionary aspects of plant-carnivore interactions. In Chadwick D.J. \& Goode J.A. (eds): Insect-Plant Interactions and Induced Plant Defence, (Novartis Foundation Symposium 223). Wiley, Chichester, pp. 3-20.

Vinson S.B., Barfield C.S. \& Henson R.D. 1977: Oviposition behaviour of Bracon mellitor, a parasitoid of the boll weevil (Anthonomus grandis). II. Associative learning. Physiol. Entomol. 2: 157-164.

WÄCKERS F.L. \& LEWIS W.J. 1994: Olfactory and visual learning and their combined influence on host site location by the parasitoid Microplitis croceipes (Cresson). Biol. Control 4: 105-112.

Wadhams L.J., Brrkett M.A., Powell W. \& Woodcock C.M. 1999: Aphids, predators and parasitoids. In Chadwick D.J. \& Goode J.A. (eds): Insect-Plant Interactions and Induced Plant Defence, (Novartis Foundation Symposium 223). Wiley, Chichester, pp. 60-73.

Received January 1, 2000; accepted May 24, 2000 